\title{
Effects of long-term ultraviolet radiation: the white form of Metridium senile (Anthozoa: Actiniaria) as a potential biological indicator for ultraviolet
}

Received: 7 January 2000 / Received in revised form: 30 May 2000 / Accepted: 5 June 2000 / Published online: 2 February 2001 (C) Springer-Verlag and AWI 2001

\begin{abstract}
Genetically identical individuals of the white form of Metridium senile were kept in the laboratory for 40 months, during almost 2 years of which they were irradiated with ultraviolet (UV) radiation simulating the shape of the solar UV spectrum. The living and experimental conditions were largely matched to the conditions in the sea anemones' natural habitat on the North Sea coast. Controls were shielded from direct radiation or irradiated with only the visible range of the spectrum; for the UV tests, the UV component corresponded either to the conditions in the natural habitat or to twice or 4 times this dose. All experiments were preceded by a severalmonth settling-in period, and UV irradiation was always begun at a low intensity. Under these conditions UV was not lethal but produced many parameter changes, of which only those that were irreversible for the entire duration of the experiment, from September 1992 to August 1994, are described here. The body mass fell significantly in all three UV-radiation modes. All irradiated animals positioned themselves so as to be less exposed to the radiation, and all changed colour from white to brown. These responses are discussed with reference to the potential of $M$. senile as an indicator or monitor for UV in the northern European coastal region. Field analyses are currently being conducted to demonstrate the extent to which the present results apply to field conditions.
\end{abstract}

Keywords Indicator - Metridium - Sea anemone . Ultraviolet-B · Ultraviolet

Communicated by K. Lüning

R. Westholt · P. Kestler · O. Sicken · W. Westheide (

University of Osnabrück, Department of Biology and Chemistry, Systematic Zoology, 49069 Osnabrück, Germany

e-mail: westheide@biologie.uni-osnabrueck.de

Tel.: +49-541-9692861, Fax: +49-541-9692587

\section{Introduction}

The increasing negative influence, direct and indirect, of anthropogenic factors throughout the biosphere demands a scientific search for indicators of these biological effects. We must know whether animals of individual species are affected by chemical and physical stressors, for example, and in what ways, in order to evaluate the risk to ecosystems. Whereas the search for standard bioassay organisms for the study of chemical pollution or organic enrichment in the marine environment already has a long history (Evans et al. 1998; Franke et al. 1998; Nicholson et al. 1998; Leemiki et al. 1999), marine organisms that can serve as useful indicators of ultraviolet (UV)-B effects are just beginning to be identified. The reasons lie in the facts that: (1) the number of potential UV indicators is small because the only viable candidates are organisms actually exposed to UV and unprotected in their natural habitat, and (2) only in recent years has it gradually been recognized that increased UV-B irradiation is indeed significant for marine aquatic habitats (e.g. Tevini 1993; Häder 1996). For instance, the UV-B impact on marine organisms was not even listed as a subject in the North Sea Quality report (North Sea Task Force Oslo and Paris Commissions 1993).

Nevertheless, it is crucially important that the search for suitable indicator organisms be actively pursued in the marine context as well. As a result of anthropogenic influences, in recent years the stratospheric ozone layer has shown clear signs of reduction, which evidently are compensated only partially and locally by an - also anthropogenic - increase in the tropospheric ozone content. Overall, then, more UV-B radiation is reaching the biosphere and is threatening organisms (Madronich 1992; Tevini 1993; Forster and Kestler 1998; Häder 1996). We now know that this applies not only to antarctic regions, where the "ozone hole" was first observed, but also to the northern European region of the northern hemisphere (Pearce 1996; UNEP 1996, 1997; Rex et al. 1997; Björn et al. 1998).

Sea anemones (Cnidaria: Anthozoa, Actiniaria) of the eulittoral and shallow sublittoral zones are among the 
Table 1 Daily duration and doses $\left(\mathrm{kJ} \mathrm{m}^{-2}\right)$ of illumination (visible range of the spectrum) over the aquaria

\begin{tabular}{|c|c|c|c|c|c|c|c|c|c|c|c|c|}
\hline Month & January & February & March & April & May & June & July & August & September & October & November & December \\
\hline $\begin{array}{l}\text { Time } \\
\text { (h) }\end{array}$ & $\begin{array}{l}800- \\
1600\end{array}$ & $\begin{array}{l}700- \\
1700\end{array}$ & $\begin{array}{l}600- \\
1800\end{array}$ & $\begin{array}{l}500- \\
1900\end{array}$ & $\begin{array}{l}400- \\
2000\end{array}$ & $\begin{array}{l}300- \\
2100\end{array}$ & $\begin{array}{l}400- \\
2000\end{array}$ & $\begin{array}{l}500- \\
1900\end{array}$ & $\begin{array}{l}600- \\
1800\end{array}$ & $\begin{array}{l}700- \\
1700\end{array}$ & $\begin{array}{l}800- \\
1600\end{array}$ & $\begin{array}{l}800- \\
1600\end{array}$ \\
\hline $\begin{array}{l}\text { Dose } \\
\left(\mathrm{kJ} \mathrm{m}^{-2}\right)\end{array}$ & 172.8 & 432.0 & 777.6 & 1209.6 & 1620 & 2073.6 & 2073.6 & 1620 & 1209.6 & 777.6 & 432.0 & 172.8 \\
\hline
\end{tabular}

few organisms in the macrozoobenthos of temperate intertidal regions, where exposure to strong sunshine is not uncommon, that lack a protective cuticle and furthermore are sessile or semisessile, so that UV could be a very important environmental stressor for them. So far individuals of five species have been studied for over 6 years in laboratory and semi-field experiments to assess the influence of UV radiation on a considerable number of parameters, and this work has been complemented by field observations (Hannack et al. 1997; Westholt et al. 1999). Of the many biological effects noted here, the only ones found to be irreversible over the entire duration of artificial UV radiation were the body mass reduction in one of the two investigated strains of Actinia equina (Westholt et al. 1999) and three parameter changes in the white morph of Metridium senile. These three parameter changes - decrease in body mass (weight), changes in positioning (i.e. increasing the angle with respect to vertical irradiation) and colour change from white to brown - are presented here as results of sublethal long-term experiments. Because the white $M$. senile, without exception, showed these UV effects in the laboratory, the species ideally meets the criteria for a potential indicator organism. Furthermore, this species has a circumpolar distribution in the northern hemisphere (Grimpe and Wagler 1940; Bucklin and Hedgecock 1982), which emphasizes its suitability as a bioindicator for this region.

\section{Materials and methods}

Experimental animals

The individuals of Metridium senile (L., 1758) used in this study were taken from a laboratory colony derived from a single juvenile specimen collected in 1978 in the tidal zone of the Ölhafen near Wilhelmshaven. The individuals of this particular strain were primarily white in the laboratory colony and attained a body mass as great as $40 \mathrm{~g}$. The strain was male and reproduced asexually by pedal laceration, with a new generation about every 3-5 months. The experimental animals belonged to about the fortieth generation.

\section{Maintenance and experimental conditions}

On 3 April 1991, ten specimens of Metridium were distributed among each of four experimental aquaria; each individual was seated on its own small granite stone, and the stones were distributed on glass platforms in such a way that the expanded tentacles of neighbouring individuals were separated by at least $5 \mathrm{~cm}$. The animals were only a few days old, and before the long-term study began, they were given time to become accustomed to the conditions in their new home.
The physico-chemical parameters of the water closely approximated those in the animals' natural habitat: salinity $1.022 \mathrm{ppm}$; $\mathrm{pH}$ 7.9-8.7; carbonate hardness 7 on the German scale; nitrate maximally $12 \mathrm{ppm}$; phosphate maximally $1.2 \mathrm{ppm}$.

Similarly, the water temperature was matched to the seasonal variations in the natural habitat. In the experimental aquaria, which communicated with one another by way of hoses, the water was thoroughly aerated and kept in motion but not filtered.

To simulate the tides, twice each day, 1000-1030 hours and 2300-2330 hours, water was pumped out of the aquaria into holding tanks and subsequently, during the periods 1600-1630 hours and $0200-0230$ hours, pumped back again. During the times of simulated low tide the animals were not covered by water, so that this arrangement approximated the microhabitats of the species that are most severely exposed to insolation in the field.

Food was presented twice daily and consisted of a seasonally varying mixture of fish flesh, crustacean larvae, rotifers, nematodes and various other invertebrates - a composition based on analyses of the gastric-cavity contents of individuals in the population of origin. All the food organisms were taken from the laboratory stocks and were still alive when introduced to the aquaria.

The aquaria were illuminated in the visible range of the spectrum (VIS), with fluorescent tubes of the small-diameter type Lumilux no. 11, True Daylight (Osram, Germany); in aquarium cultures generally, these are successfully used even for keeping zooxanthellae-bearing organisms. The light intensity (VIS) at the animals' top position on the glass platforms was measured with a radiometer (LiCor Quantum radiometer, LI/580B; Licor, Lincoln, Neb.) and adjusted, by altering the number and distance of the fluorescent tubes, to correspond to the diurnal and annual fluctuations outdoors (Table 1).

All individuals were weighed (wet weight) at intervals of 30 days, i.e. at the end of each month, between April 1991 and August 1994, and the angle between the body long axis and the vertical was measured. The body colours of the individuals were continually monitored by comparison with RAL colour tables (RAL, German Institution for Quality Specifications and Marking, Sankt Augustin, Germany).

UV irradiation and criteria for selecting the animals in the long-term experiments

The UV sources used in the irradiation experiments were UVA340 fluorescent tubes (Q-Panel, USA), suspended at specific distances directly above the aquaria. They emit a quasisolar UV-B spectrum (Fig. 1), and are thus eminently suitable to simulate solar UV-B radiation. The radiation intensities (Watts per metre squared) and doses (Joules per metre squared) used in the experiments were selected to correspond to the solar UV-A and UV-B values measured in a microhabitat within the range of the original population of $M$. senile (Ölhafen near Wilhelmshaven) that a few years ago was still occupied by numerous individuals. Mode $1 \mathrm{X}$ corresponds approximately to the radiation conditions to which the animals there were exposed in the course of the day and the year: e.g. $0.5 \mathrm{~W} \mathrm{~m}^{-2} \mathrm{UV}-\mathrm{B}(280-320 \mathrm{~nm})$ for a cloudless summer day measured with a UV-A/B-Meter no. 1533 (Hönle, Martinsried, Germany), $0.525 \mathrm{~W} \mathrm{~m}^{-2}$ compared to a Macam Spectroradiometer SR9910 (Macam Spectroradiometer, Livingston, Scotland). In the radiation modes $2 \mathrm{X}$ and $4 \mathrm{X}$, the radiation was twice and 4 times as intense, respectively (Fig. 2). The UV intensities were measured 
Fig. 1 Spectrum of the solar simulation in the laboratory compared to the global radiation in the natural habitat of a Metridium population. The continuous curve shows the spectrum of the Q-Panel UVA340 (Q-Panel, USA) used as an ultraviolet (UV) source, and the dot-dashed curve shows the spectrum of the Lumilux True Daylight (Osram, Germany) source used to simulate the visual region of the spectrum. The reference curve (dashed) represents a solar spectrum recorded with a MACAM spectroradiometer on 13 September 1999 at the water surface in a natural habitat of Metridium senile on the north side of an enclosed swimming area in the outer harbour at Wilhelmshaven, Germany

Fig. 2 Daily UV-A dose and UV-B dose. Irradiation mode $1 \mathrm{X}$ approximates intensities and durations of UV radiation measured at an intertidal site on the German North Sea coast (Ölhafen, near Wilhelmshaven). Intensities of irradiation modes $2 \mathrm{X}$ and $4 \mathrm{X}$ were twice and 4 times as high, the durations remaining the same
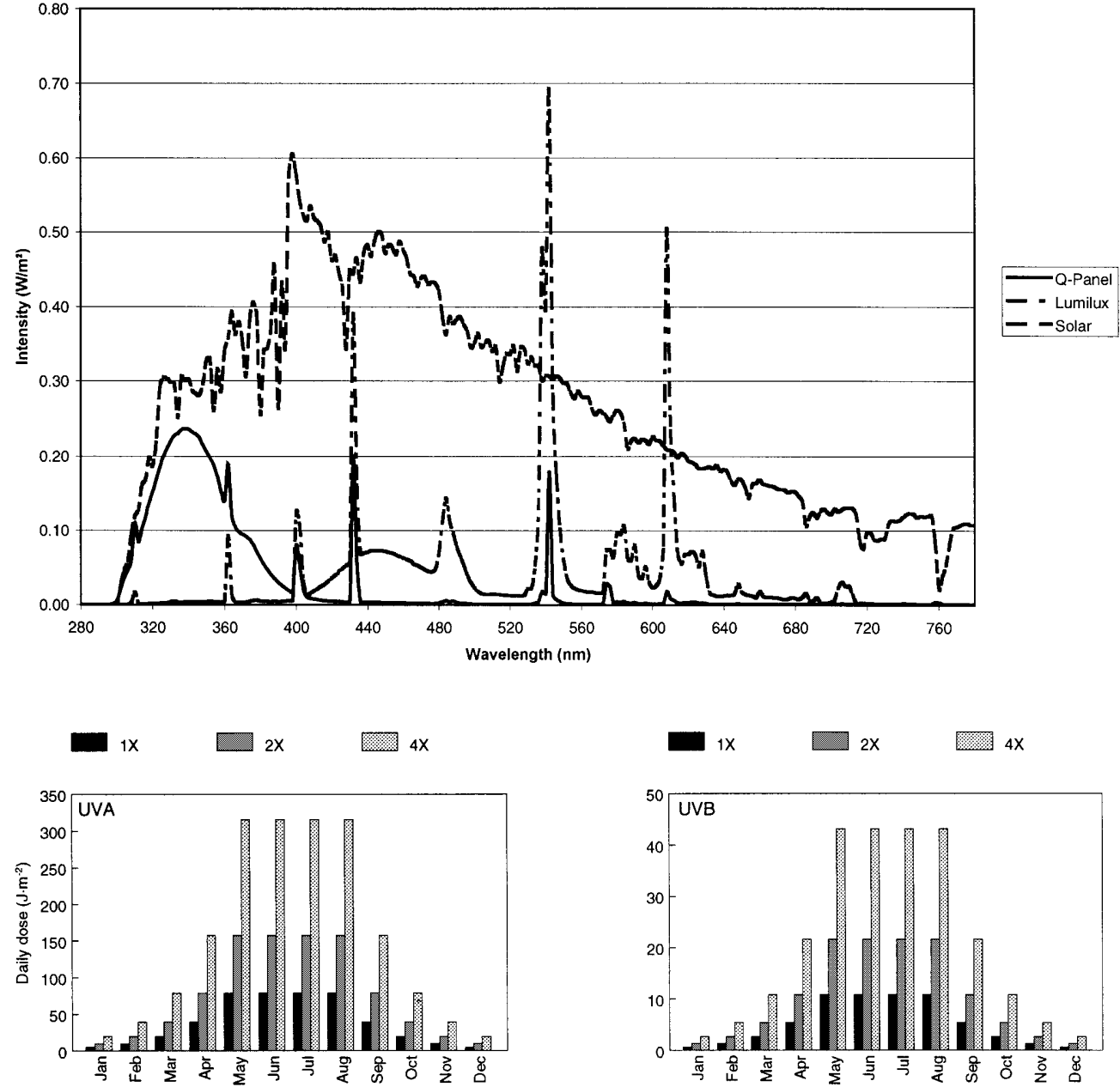

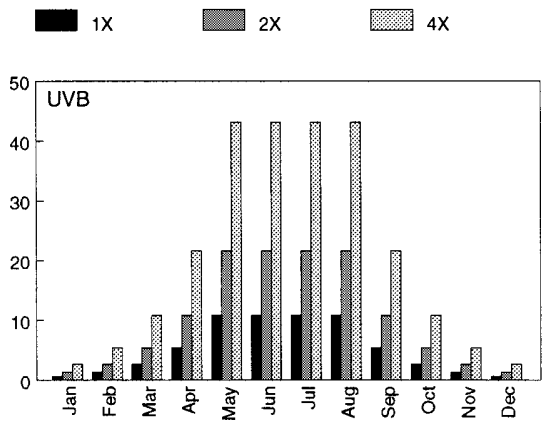

with a UV-A/B meter that detects UV-B radiation in the range 280-320 nm. As defined by the Commission Internationale d'Eclairage (CIE 1989), however, the UV-B spectral region extends from 280 to $315 \mathrm{~nm}$. Therefore the UV-B values given here for the constant parameters in the laboratory should be corrected downwards by a factor of 1.8 to conform to international standards (adjustment to values measured with the MACAM-Spectroradiometer, UV-B 280-315 nm).

Because constant UV irradiation would be inconsistent with the natural situation at the North Sea coast, in all radiation modes the daily doses were varied in a 4-day rhythm by adjusting the distance between the lamps and the experimental animals, so that the intensity varied as follows: first day $80 \%$, second day $100 \%$, third day $120 \%$, fourth day $100 \%$. The UV radiation was not presented at the full intensity of the corresponding mode at the outset, but was gradually increased. The reason was that pilot experiments had shown that in radiation mode $4 \mathrm{X}$, all the animals experiencing sudden UV stress after the settling-in period were killed within about 34 days. Furthermore, animals irradiated immediately after they had been collected from their habitat, with no settling-in period, responded in entirely unreproducible ways.

In one of the four experimental aquaria the sea anemones on the platforms were not irradiated; these served as illumination controls $(0 \mathrm{X})$ for comparison with the UV-irradiated (1X, 2X, 4X) individuals. In addition one control animal (CA) was positioned below the platforms to provide identical local water conditions (e.g. dissolved organic matter, chemical ecofactors such as oxygen radicals and oral food supply) but protection from direct illumination by the sand layer on the platforms (only $5 \%$ of the visible-radiation dose) [see Fig. 2 in Westholt et al. (1999)].
Before starting the UV experiment all the individuals had to satisfy the following criteria to confirm that the adjustment to their maintenance had been successful: (1) when supplied with a mass of food corresponding to their body mass, they should digest it completely within $12 \mathrm{~h}$; (2) they should reach a relatively uniform, strain-specific body mass optimal for the aquarium conditions, and this mass should remain quite stable $( \pm 20 \%)$ over a period of months; (3) during the activity phase they should have all their tentacles fully expanded.

\section{Data processing}

For processing, data obtained as described above were entered into Excel spreadsheets (Microsoft, Munich) then used to find means, SDs and sums. The graphs were produced with the program Slide-Write Plus (Indigo Informationssysteme, Munich). Where differences were found between the parameters of interest, significance was checked by using ANOVA and multiple ANOVA (MANOVA). Before these statistical tests were applied, the data were checked for normal distribution with the KolmogorovSmirnov test and for equality of variance with the Levene test. These statistical procedures were carried out with SPSS for Windows (SPSS Software, Munich). 


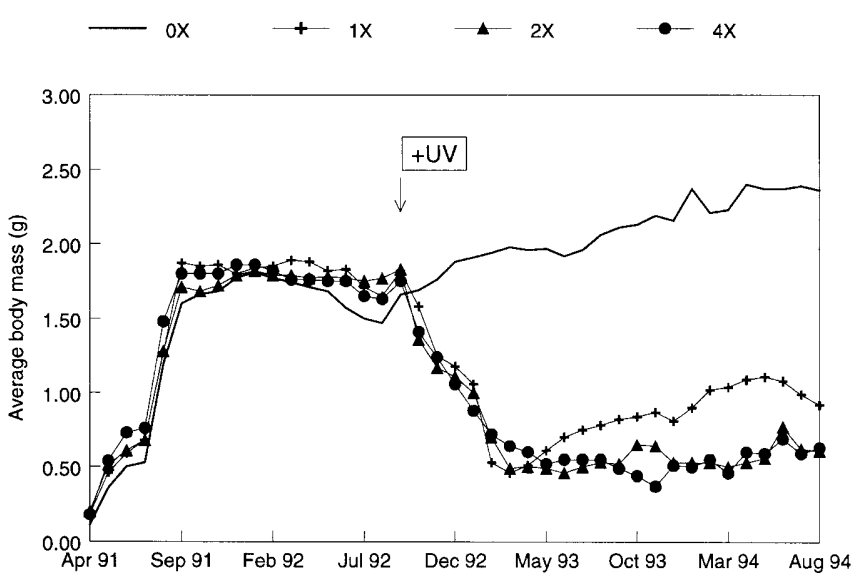

Fig. 3 Monthly averages of body mass (grams) of Metridium senile. UV irradiation onset $(+U V)$ in October 1992 for modes $1 \mathrm{X}$, $2 \mathrm{X}$ and $4 \mathrm{X} ; n=10$ for each irradiation mode

\section{Results}

Body mass

The sea anemones in the aquaria intended for UV exposure grew in body mass at a rate comparable to the control animals up to the onset of irradiation (in October 1992). The body mass of all the M. senile was $<0.5 \mathrm{~g}$ when the aquaria were first set up in April 1991; by September 1991 it had increased to $1.65 \pm 0.32 \mathrm{~g}$ (Fig. 3), and from then until the beginning of UV irradiation (October 1992) it remained approximately constant.

With the onset of UV exposure the body mass of the individuals under the conditions $1 \mathrm{X}, 2 \mathrm{X}$ and $4 \mathrm{X}$ began to decline, and within half a year (by March 1993) it had reached the significantly lower level of $0.53 \pm 0.11 \mathrm{~g}$. The progress of mass loss was about the same, regardless of radiation mode (MANOVA, $P>0.05$ ); from November 1992 until the experiment was terminated (August 1994) all the UV-irradiated sea anemones had a highly significantly lower body mass than the control animals (ANOVA, $P<0.001$ ). Hence under these experimental conditions there was no dependence of body mass loss on either the UV intensity (1X-4X) or the UV dose to which the anemones were exposed in the three spectral modes; with each spectral mode the body mass loss amounted to $67.94 \pm 0.37 \%$ of the initial body mass. The results also revealed no correlation with the simulated seasonal variation in UV irradiation.

However, the $1 \mathrm{X}$ animals began to regain weight slightly towards the end of the experiment and grew to $0.92 \pm 0.21 \mathrm{~g}$, so that from February 1994 on they were significantly heavier than the $2 \mathrm{X}$ and $4 \mathrm{X}$ individuals (ANOVA, $P<0.001$ ).

In the anemones exposed only to visible light (0X) no body-mass reduction occurred; in fact, these $0 \mathrm{X}$ animals became slightly heavier (up to $2.36 \pm 0.15 \mathrm{~g}$ towards the end of the experiment). The body mass of the largely unilluminated CA did not differ significantly from that of the $0 \mathrm{X}$ controls (Fig. 4; ANOVA, $P>0.05$ ).

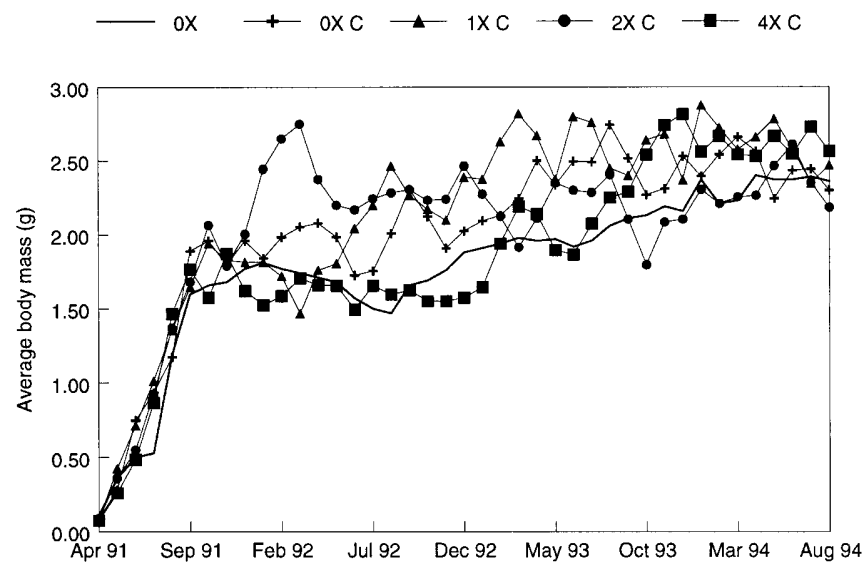

Fig. 4 Monthly averages of body mass (grams) of the control animals $(C A)$ and the illumination controls $(O X)$ of $M$. senile. The control animals $(0 \mathrm{X} \mathrm{K}, 1 \mathrm{X} \mathrm{K}, 2 \mathrm{X} \mathrm{K}, 4 \mathrm{X} \mathrm{K})$ were seated in the aquaria below the platforms carrying the $0 \mathrm{X}, 1 \mathrm{X}, 2 \mathrm{X}$ and $4 \mathrm{X}$ animals. $0 \mathrm{X}$ animals, $n=10$; control animals, $n=1$ for each irradiation mode

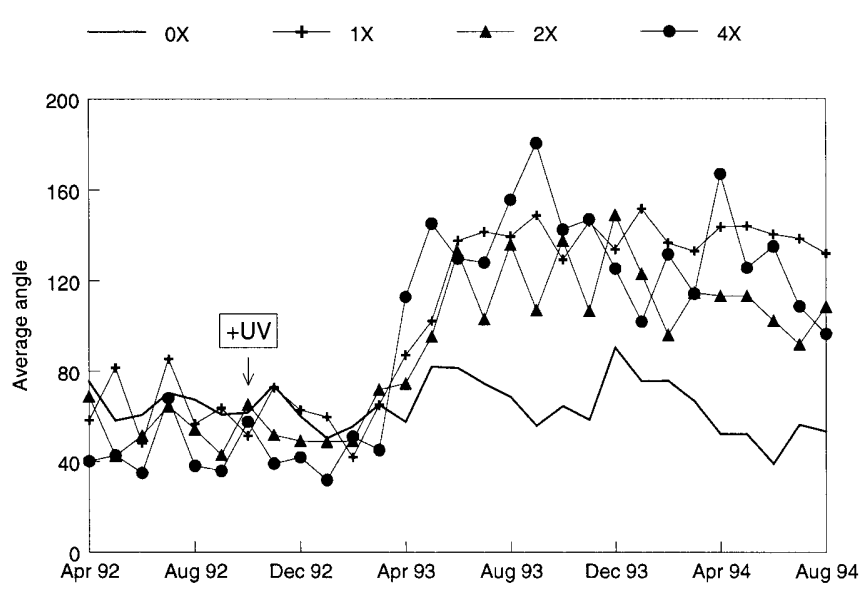

Fig. 5 Positioning of $M$. senile with respect to the incident radiation, depending on irradiation mode; $n=10$ for each irradiation mode

\section{Positioning}

As another parameter, the positioning of the animals was examined - i.e. the angle between the long axis of their bodies and the vertically incident radiation (Fig. 5).

At the beginning of the experiment all individuals were standing upright, so that their upper surfaces were directly exposed to the radiation. During the initial period, and even after the first 6 months, occasionally slight changes in positioning appeared in the different radiation modes, so that in some cases significant differences were evident (ANOVA, $P<0.05$ ). However, these changes were only spontaneous and brief. From April 1993 on, all the UV-irradiated anemones increased their angle to the vertical, whereas the $0 \mathrm{X}$ animals retained their positions. The largest positional changes were made by the 4X animals, which from April to June 1993 adopted significantly larger angles to the vertical in their choice of 


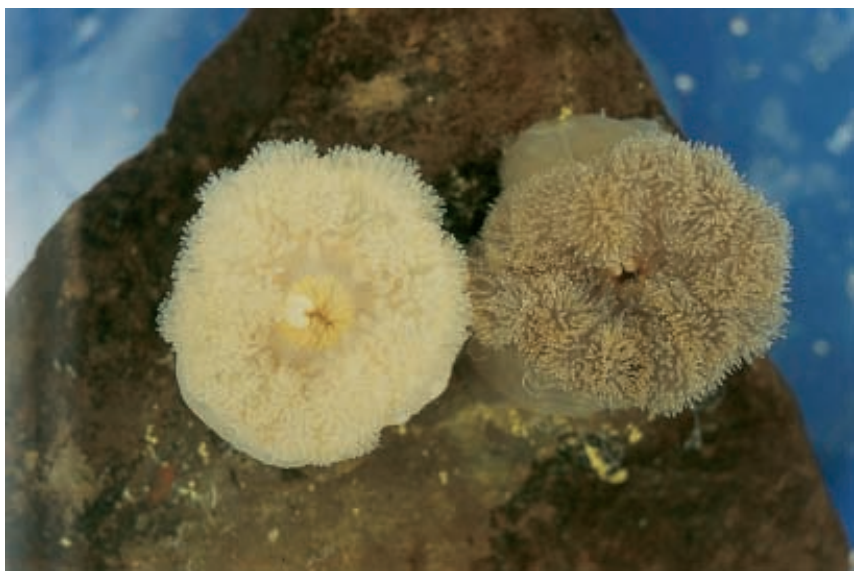

Fig. 6 The UV-specific brown-coloration of M. senile. Left a white individual at the beginning of the long-term experiment is shown, right a brown individual at the end of the experiment

position than did the other anemones (ANOVA, $P<0.001)$. From July 1993 until the end of the experiment in August 1994, all the M. senile exposed to UV positioned themselves at a greater angle to the vertical than did the $0 \mathrm{X}$ animals. During this period the sea anemones stressed by UV varied their positioning more widely, so that in some cases significant differences between the three UV modes appeared (ANOVA, $P<0.05$ ). These differences, again, were spontaneous and not long-lasting. Again, no UV dose dependence could be demonstrated, nor were there any changes correlated with the annual variation in UV radiation.

\section{Colour changes}

The body coloration of $M$. senile was specified by visual comparison with the RAL colour tables, and each animal was assigned to one of two colour ranges. Colour range 1 included those best matched by the following colours: RAL 1013 pearl white, RAL 1015 light ivory, RAL 9001 cream white, and RAL 9016 traffic white. The colours in range 2 were: RAL 7013 brown-grey, RAL 8007 fawn, RAL 8008 olive brown, RAL 8014 sepia, and RAL 8016 mahogany.

Until the end of December 1992 all individuals in the long-term experiment were assignable to colour range 1 . The individuals of radiation mode $0 X$ retained this colour range throughout the long-term experiment. From March 1993 on, however, the coloration of all individuals of radiation modes $1 \mathrm{X}, 2 \mathrm{X}$ and $4 \mathrm{X}$ had shifted into range 2: i.e. they had become dark (Fig. 6). In some individuals the colour change occurred gradually and uniformly over the whole body; in others it was first manifest as brown stripes or spots, which then expanded. The UV-specific brown coloration subsequently remained stable and was irreversible for the duration of the experiment; it was also independent of the mode of radiation.
The brown coloration was passed on to the next asexually produced generations, even though these generations were not UV-irradiated. Not until the sixth generation did the brown coloration fade to a shade of grey.

\section{Discussion}

Organisms protect themselves from UV by external filters, for instance by changing habitats, avoidance behaviour and various protective structures on the body surface. UV-absorbing pigments provide an internal filter. When sufficient UV-B radiation penetrates even this protective filter, the result is primary damage to macromolecules (stress), which may activate molecular repair mechanisms and lead to regeneration of the damaged cells. The amount of physiological strain so produced determines whether the organism will survive.

The present results are derived from experiments in which - as in experiments on Actinia equina (Westholt et al. 1999) - the influence of UV on M. senile was investigated under conditions especially designed to approximate the situation in their natural habitat. Sea anemones in general are characterized by a long life span, so that with $M$. senile it was possible to carry out experiments lasting several years. Such long-term trials reveal effects that would have remained undiscovered in experiments with a duration of a few weeks or months. For instance, whereas the body-mass reduction was demonstrable shortly after the onset of UV irradiation, the positional change appeared months later. Another feature of this experimental strategy was to allow the animals ample time to become accustomed to the laboratory conditions; the tests were not begun until parameters such as body mass had stabilized sufficiently that for several months there were no major fluctuations. As a result, the possibility that stressors other than UV contributed to the results can be substantially ruled out.

Yet another characteristic aspect of the experimental strategy was the care taken to make the ambient radiation as similar as possible to that in the natural habitat, including seasonal variation. We employed the Q-Panel UVA340 as a UV source. This lamp has weaknesses in the UV-A part of the spectrum, where it does not reach intensity levels as high as those in the solar radiation. However, it reproduces very precisely the UV-B intensity curve, especially in the short-wavelength region of the spectrum. In this regard it provided the best solar simulation of all the lamps tested. A still better simulation of solar radiation can be achieved with xenon light sources, but these are not suitable for large-area homogeneous irradiation of an aquarium system. The $400 \%$ increase in mode $4 \mathrm{X}$, to a UV-B intensity of $2 \mathrm{~W}$ $\mathrm{m}^{-2}$, is unusually large in an experimental context, but such intense radiation is actually the rule in tide pools on flat North Sea beaches under full sunlight. Because M. senile also lives there, even in the field these animals are in fact exposed to such high intensities at low tide.

The long-term investigation described here shows how this species of sea anemone employs three adapta- 
tion mechanisms to reduce the amount of UV radiation entering the body or to escape from or protect themselves from such radiation, so that they can expand the scapus and tentacles with less or no risk. For instance:

1. The body-mass reduction can be interpreted as a means of reducing the size of the body and hence the surface area accessible to radiation.

2. Changing position, under these experimental conditions, is the only means by which the anemones could escape from the radiation into shaded regions of their habitat or to use the water attenuation of UV-B as an external filter.

3. The brown coloration is probably produced by incorporating pigment granules into the epidermal cells (unpublished ultrastructure investigation), where they presumably act as a shield against UV. The brown pigment is probably melanin, which long ago was reported to be present in $M$. senile (Fox and Pantin 1941). Other protective pigments such as mycosporine-like amino acids, which have been found in certain other marine organisms (Hannach and Sigleo 1998; Banaszak et al. 1999; Karsten et al. 1999), could not be demonstrated in this species. Altogether, a great variety of parameter changes were observed following the onset of UV irradiation, including alterations in the timing of sperm release, in the number and body mass of asexually produced offspring, in tentacle formation and in the animals' readiness to feed. Only the three parameters described above were significantly and irreversibly changed under UV irradiation in the period of the experiment: (1) the reduction in body mass, (2) the change in position with respect to the direction of incidence of UV radiation, and (3) the brown coloration.

The possibility cannot be excluded that in the field other factors, acting alone or in combination with UV radiation, could elicit one of the parameter changes described above. However, further experiments with other stressors - a brief list of which includes elevated water temperature, organic contamination of the water (nitrates), substituting saltwater by freshwater for a few hours or interruption of the food supply - have shown that these do not induce the three parameter changes simultaneously. Cessation of feeding and severe nitrate contamination merely caused a loss of body mass, and this was distinctly less pronounced than the $67 \%$ loss observed for UV irradiation. We therefore infer that $M$. senile is suitable for long-term UV monitoring in the field.

The irreversibility of these changes under long-term UV conditions qualifies $M$. senile as a potential indicator and monitor organism. This applies on one hand to active monitoring, in which anemones of standard size, the origin and previous treatment of which are known, are introduced to ecosystems. Initial experiments of this kind have already been successfully performed under semi-field conditions. The species also, and still more importantly, appears suitable for passive UV monitoring, in which individuals are observed in their natural habitat and from their exposure, size and coloration the danger presented by UV at that site is inferred directly.

If bioindicators are defined as organisms or communities, the visible features of whose lives can be closely correlated with certain environmental factors, then they can be used as estimators of these factors (Schubert 1991). The term bioindicator encompasses a broad spectrum of types of indication (Arndt et al. 1987; Arndt 1992): information may be derived from an organism's accumulation of substances or from its reaction, and the members of each of these categories can be used as indicator, test or monitor organisms. Primary criteria for a UV indicator are that it must be an organism that gives a reproducible response to the stressor, that its responses to stimuli of different intensity are detectably different, and that there is a clear threshold for its response (Mülleder et al. 1992; Keitel 1989). Furthermore, the response must be specific to a particular stimulus, in this case to UV-B radiation. $M$. senile meets these criteria: these anemones respond directly to UV-B by contracting the body, the response is intensity dependent (Sicken and Kestler 1999; O. Sicken unpublished data), and it is elicited only above a certain threshold level. Furthermore, under UV radiation $M$. senile shows the parameter changes in the described way.

$M$. senile can thus be regarded as a potential animal indicator organism for UV in the marine environment, as various species of macroalgae - Delessaria sanguinea (Dring et al. 1996); Porphyra umbilicalis and Palmaria palmata (Cordi et al. 1999) - have been shown to be. That such indicators should be available for estimating damage and other effects exerted by UV on marine habitats is evident from many studies on the ways UV-B affects marine organisms (Beland et al. 1999; Kouwenberg et al. 1999a, 1999b; Mostajir et al. 1999).

Acknowledgements Dr R. Forster, Rostock, is acknowledged for spectroradiometric measurements and valuable advice. We thank Prof. Dr R. J. Paul, Münster, for providing us with an UV-B radiometer (IL 1400A) for control purposes. This work was supported by research grant BEO 71/03F0120B Wirkung von UV-Strahlung auf marine Organismen (UV-MAOR) of the German Federal Ministry of Training and Research (BMBF). The authors thank Dr. Irmisch, BEO, Warnemünde, who organized the project, and Mrs Andrea Noël, who skilfully typed the manuscript.

\section{References}

Arndt U (1992) Einführung in die Bioindikation. In: Köhler A, Arndt U (eds) Bioindikatoren für Umweltbelastungen, vol 24. Hohenheimer Umwelttagung, Margraf, Weihersheim, pp 13-18

Arndt U, Nobel W, Schweizer B (1987) Bioindikatoren. Möglichkeiten, Grenzen und neue Erkenntnisse. Ulmer, Stuttgart

Banaszak AT, Lesser MP, Kuffner IB, Ondrusek M (1999) Relationship between ultraviolet (UV) radiation and mycosporinelike amino acids (MAAs) in marine organisms. Bull Mar Sci 63:617-628

Beland F, Browman HI, Rodriguez CA, Stpierre JF (1999) Effect of solar ultraviolet radiation $(280-400 \mathrm{~nm})$ on the eggs and larvae of atlantic cod (Gadus morhua). Can J Fish Aquat Sci 56:1058-1067 
Björn LO, Callaghan TV, Gehrke C, Johanson U, Sonesson M, Gwynn-Jones D (1998) The problem of ozone depletion in northern Europe. Ambio 27:275-279

Bucklin A, Hedgecock D (1982) Biochemical genetic evidence for a third species of Metridium (Coelenterata: Actiniaria). Mar Biol 66:1-7

Commission Internationale d'Eclairage (CIE) (1989) International lighting vocabulary. CIE publication no. 17.4, 4th edn. CIE, Wien

Cordi B, Hyde P, Donkin ME, Price DN, Depledge MH (1999) Evaluation of in vivo thallus absorptance and chlorophyll fluorescence as biomarkers of UV-B exposure and effects in marine macroalgae from different tidal levels. Mar Environ Res 48:193-212

Dring JD, Wagner A, Boeskov J, Lüning K (1996) Sensitivity of intertidal and subtidal red algae to UVA and UVB radiation, as monitored by chlorophyll fluorescence measurements: influence of collection depth and season, and length of irradiation. Eur J Phycol 31:293-302

Evans SM, Nicholson GJ, Browning C, Hardman E, Seligman O, Smith R (1998) An assessment of tributylin contamination in the north Atlantic using imposex in the dogwhelk Nucella lapillus (L.) as a biological indicator of TBT pollution. Invert Reprod Dev 34:277-287

Forster RM, Kestler P (1998) Flora und Fauna unter einer verstärkten UV-B-Strahlung. In: Lozan JL, Graßl H, Hupfer P (eds) Warnsignal Klima/Wissenschaftliche Fakten. Wissenschaftliche Auswertung in Kooperation mit GEO, Hamburg, pp 303-306

Fox P, Pantin CFA (1941) The colours of the plumose anemone Metridium senile (L.). Phil Trans $\mathrm{R}$ Soc London Ser B 230:415-450

Franke HD, Gutow L, Janke M (1998) The recent arrival of the oceanic isopod Idotea metallica (Bosc) off Helgoland (German Beight, North Sea): an indication of a warming trend in the North Sea? Helgol Wiss Meeresunters 52:347-357

Grimpe G, Wagler E (1940) Tierwelt der Nord- und Ostsee. Bd. IIIe $_{2}$ Anthozoa II. Becker und Erler, Leipzig

Häder D-P (1996) Effects of enhanced solar UV-B radiation on phytoplankton. Sci Mar [Suppl] 60:59-63

Hannach G, Sigleo AC (1998) Photoinduction of UV-absorbing compounds in six species of marine phytoplankton. Mar Ecol Prog Ser 174:207-222

Hannack K, Kestler P, Sicken O, Westheide W (1997) On the influence of UV-radiation on number and ultrastructure of the endosymbiontic dinoflagellates in the sea anemone Cereus pedunculatus (Anthozoa: Actiniaria). Helgol Wiss Meeresunters 51:487-502

Karsten U, Bischof K, Hanelt D, Tüg H, Wiencke C (1999) The effect of ultraviolet radiation on photosynthesis and ultraviolet-absorbing substances in the endemic arctic macroalga $D e$ valeraea ramentacea (Rhodophyta). Physiol Plant 105:58-66

Keitel A (1989) Praxiserprobte Bioindikationsverfahren. StaubReinh. Luft 49:29-34

Kouwenberg JHM, Browman HI, Cullen JJ, Davis RF, Stpierre JF, Runge JA (1999a) Biological weighting of ultraviolet $(280-400 \mathrm{~nm})$ induced mortality in marine zooplankton and fish. I. Atlantic cod (Gadus morrhua) eggs. Mar Biol $134: 269-284$
Kouwenberg JHM, Browman HI, Runge JA, Cullen JJ, Davis RF, Stpierre JF (1999b) Biological weighting of ultraviolet $(280-400 \mathrm{~nm})$ induced mortality in marine zooplankton and fish. II. Calanus finmarchicus (Copepoda) eggs. Mar Biol 134:285-293

Leemiki CHH, Yamaguchi Y, Maekawa T, Zhang ZN, Seki H (1999) Endoscope application for the mussel watch program of marine pollution monitoring. Water Air Soil Pollut 114:53-66

Madronich S (1992) Implications of recent total atmospheric ozone measurements for biologically active ultraviolet radiation reaching the earth's surface. Geophys Res Lett 19:37-40

Mostajir B, Demers S, Demora S, Belzile C, Chanut JP, Gosselin M, Roy S, Villegas PZ, Fauchot J, Bouchard J, Bird D, Monfort P, Levasseur M (1999) Experimental test of the effect of ultraviolet-B radiation in a planktonic community. Limnol Oceanogr 44:586-596

Mülleder N, Gross H, Arndt U (1992) Wirkungsbezogene Messung von Ozon - Ein Vergleich der Reaktion von Tabak BelW3 und Indigo. In: Köhler A, Arndt U (eds) Bioindikatoren für Umweltbelastungen, vol 24. Hohenheimer Umwelttagung, Margraf, Weihersheim, pp 49-61

Nicholson GJ, Evans SM, Palmer N, Smith R (1998) The value of imposex in the dogwhelk Nucella lapillus and the common whelk Buccinum undatum as indicators of TBT contamination. Invert Reprod Dev 34:289-300

North Sea Task Force Oslo and Paris Commissions (eds) (1993) North Sea quality status report. Olsen and Olsen, Fredensborg, Sweden

Pearce F (1996) Big freeze digs a deeper hole in ozone layer. New Sci 149:7-10

Rex M, Harris NRP, Von der Gathen P, Lehmann R, Braathen GO, Reimer E, Beck A, Chipperfield MP, Alfier R, Allaart M, OConnor F, Dier H, Dorokhov V, Fast H, Gil M, Kyro E, Litynska Z, Mikkelsen IS, Molyneux MG, Nakane H, Notholt J, Rummukainen M, Viatte P, Wenger J (1997) Prolonged stratospheric ozone loss in the 1995-96 Artic winter. Nature 389:835-837

Schubert R (1991) Bioindikation in terrestrischen Ökosystemen, 2nd edn. Fischer, Stuttgart

Sicken O, Kestler P (1999) Immediate UV-B-specific behavioural response of Metridium senile (Cnidaria, Anthozoa). Verh Ges Ökol 29:491-495

Tevini M (1993) UV-B radiation and ozone depletion. Effects on humans, animals, plants, microorganisms, and materials. Lewis, Boca Raton, Fla.

UNEP (1996) Environmental effects of ozone depletion. Executive summary 1996. United Nations Environment Programme, Geneva

UNEP (1997) Environmental effects of ozone depletion. Interim summary, September 1997. United Nations Environment Programme, Geneva

Westholt R, Kestler P, Sicken O, Westheide W (1999) Influence of sublethal long-term UV irradiation on body mass, reproduction and behaviour of north European Actinia equina. J Mar Biol Assoc UK 79:1-10 